Review Article

\title{
Status of Cancer Research in India
}

\author{
PHULEN SARMA ${ }^{1}$, PARSHANT SHARMA ${ }^{3}$, RAHUL SINGH ${ }^{2}$, ABHISHEK MISHRA ${ }^{1}$, HARISH \\ KUMAR $^{1}$, ANUSUYA BHATTACHARYYA ${ }^{4}$, DIBBANTI HARIKRISHNAREDDY ${ }^{1}$, ASHUTOSH \\ SINGH $^{1}$ and BIKASH MEDHI ${ }^{1, *}$ \\ ${ }^{1}$ Department of Pharmacology, PGIMER, Chandigarh, ${ }^{2}$ Department of Gastroenterology, PGIMER, \\ Chandigarh, ${ }^{3}$ Department of Nuclear Medicine, PGIMER, Chandigarh, ${ }^{4} \mathrm{SSN}$, Guwahati
}

(Received on 04 August 2017; Accepted on 20 November 2017)

\begin{abstract}
Burden of cancer in India is increasing day by day. Projected number of new cancer cases in 2016 is 1,219,649. This brings with it the need for research to investigate different India specific risk factors, mechanistic pathways, role of traditional herbal medicine, efficacy of different agents, comparative evaluation of me too agents etc. To evaluate the current status of cancer research in India, we have searched different databases like CTRI, clinicaltrials.gov, PubMed etc. regarding different publications on this topic from India. Number and quality of preclinical studies are very good, but the number of clinical studies published or registered are very less, compared to preclinical studies. North eastern states like Manipur, Mizoram are lagging behind in cancer research. We need infrastructure development to promote research in those states.
\end{abstract}

Keywords: Cancer; Research; Clinical; Pre-clinical; India

\section{Introduction: Cancer Burden in India}

Cancer is a major cause of morbidity, mortality and socio-economic burden in India (Sullivan et al., 2014). To address the epidemiological issues in Indian population, National Cancer Registry Program (NCRP) is functioning since 1991. NCRP brought out a special concept called atlas of cancer for geographic region wise mapping of cancer. It is basically divided into hospital based and population based registry. The 2007-2011 report included 7 centers (hospital based) (National cancer registry, 2007-2011 report).

The projected number of new cancer cases by 2016 is $1,219,649$ and the number of cancer cases is increasing $(1,058,984$ in 2011). The estimated cancer incidence was slightly greater in females. Certain types of cancer (e.g. esophagus, lung, stomach, oral and pharyngeal cancers) were higher in man while cervix and breast cancer was most important in females followed by oral, gastric and esophagus (Murthy et al., 2008). Contribution of India towards global cancer burden is $7.8 \%$ and towards global cancer death is $8.33 \%$ (Saranath et al., 2014).

The rising number of new cancer cases highlights the importance of cancer research in India. The necessity ranges from studies to determine the carcinogens, basic research techniques to evaluate different molecular pathways and new drugs for treatment or drug repurposition. In this context, we have reviewed the status of current cancer research in India.

To access the status of cancer research in India, we divided them into preclinical and clinical research.

\section{Status of Preclinical Research in India}

Many Indian universities, medical colleges, pharmaceutical colleges and research centers are involved in preclinical research and many of them are involved in cancer research, drug discovery and development, evaluation of etiopathology and molecular characterization of it. Few of the most explored research in cancer therapeutics are breast cancer, colorectal cancer, leukemia, brain cancer, lung cancer, cancer cervix and hepatocellular cancer. High 
quality researchis also going on in other types of cancers. Below we have discussed about progress of preclinical research in few targeted areas. Data is presented in tabular form in Table 1.

\section{Breast Cancer}

Basu et al. (2017) from Chittaranjan National Cancer Institute, Kolkata, evaluated the cancer chemo preventive potential of vanadium-based compound vanadium(III)-1-cysteine as an add on to cyclophosphamide in mice bearing breast adenocarcinoma cells. They showed that the combined treatment significantly reduced the tumor burden and enhanced survival by promotion of apoptosis and blocking of angiogenesis. Shavi et al. (2017) from Manipal college of pharmaceutical Sciences, Manipal university, Manipal in collaboration with pharmaceutical and molecular biotechnology research centre, Waterford Institute of Technology of Ireland, developed PLA microspheres which demonstrated the feasibility of employing as biodegradable depot polymeric microspheres of anastrozole for long-term treatment of breast cancer. Damineni et al. (2017) from Indian Institute of Science, Bangalore noticed that a good proportion of patients with lymph node positivity remain disease free for 5 years or more, while about a third of those who were lymph node negative develop distant metastasis within the same period. They found that primary breast cancers showing expression profile of TMP-28 (tripartite motifcontaining protein-28) was associated with metastasis, stemness, resistance to chemotherapy and growth of tumor. Bhale et al. (2017) from School of Chemical Sciences (Solapur University), established the anticancer activity of extended conjugated indolylchalcones. Nair et al. (2017) from Rajiv Gandhi Centre for Biotechnology, Kerala evaluated the molecular trail of anticancer property of a novel copper carbohydrazone complex in a panel of cell lines with either wild or mutated BRCA-1 [HCC-1937 (BRCA1 ${ }^{-}$ /ER $\left.\alpha^{-}\right)$, MCF-7 (BRCA1 $\left.{ }^{+} / \mathrm{ER}^{+}\right), \mathrm{HCC} 1937 / \mathrm{wt}$ BRCA1, MX1 (BRCA1- /ER $\alpha^{-}$), MDA-MB-231 $\left(\mathrm{BRCA}^{+} / \mathrm{ER}^{-}\right), \mathrm{MDA}-\mathrm{MB}-436\left(\mathrm{BRCA}^{-} / \mathrm{ER}^{-}\right)$ cell lines]. $\left.\mathrm{Cu}_{2}(\mathrm{HL})\left(\mathrm{HSO}_{4}\right) \dagger \cdot \mathrm{H}_{2} \mathrm{O}\right] \mathrm{SO}_{4}+6 \mathrm{H}_{2} \mathrm{O}$ (CS2) was found to be the most potent as anticancer agent amongst all the agents evaluated. They further gave evidence that CS2 binds to DNA and induces DNA damage and resultant strand breaksas assessed by expression of $\gamma-\mathrm{H} 2 \mathrm{AX}$. Kumar et al. (2016) from
Centre for Biomedical Engineering, Indian Institute of Technology Delhi, established the role of trastuzumab and folic acid conjugated redoxresponsive random multiblockco-polymericnano carriers for treatment of breast cancer.

Other labs or institutes actively working in this field are Bharathiar University (Proteomics and molecular cell physiology Lab of Department of Zoology, School of Life Sciences, Coimbatore), Periyar University (Salem, Tamil Nadu), CDRI Lucknow, Central University of Kerala, (Kasaragod, Kerala), NIPER-Hyderabad (Department of Pharmacology \& Toxicology), Babasaheb Bhimrao Ambedkar University (Department of Pharmaceutical Sciences, School of Biosciences and Biotechnology, Lucknow), Nirma University (Institute of Pharmacy, Ahmedabad, Gujarat), Bharathiar University (School of Life Sciences, Coimbatore, Tamil Nadu) and Pharmaceutical Nanotechnology Research Laboratory (ISF College of Pharmacy, Punjab).

\section{Colorectal Cancer}

Jyoti et al. (2016) from department of pharmaceutics, Chandigarh College of Pharmacy, Punjab evaluated the role of chitosan microsphere amalgamated curcumin-2-HP- $\beta-C D$ complex for selective delivery to colon by oral route. In preclinical pharmacokinetic studies, this chitosan microsphere amalgamated complex of curcumin with $2-\mathrm{HP}-\beta-\mathrm{CD}$ enhanced colonic targeting of curcumin (8.36 times) compared to suspension of curcumin.

NF- $\kappa$ Bis an important mediator of angiogenesis in colorectal cancer. Curcumin inhibits NF- $\kappa B$. Going with this hypothesis, Rajitha et al. (2017) from Banasthali University (Department of Microbiology) in collaboration with Berhampur University (Odisha) and Emory University, (Georgia) evaluated the effect of curcumin and two synthetic analogues of it (UBS109 and EF31) on angiogenesis associated with colorectal cancer (HT-29 and HCT116 cell lines). Treatment by curcumin and its synthetic analogues resulted in decrease in angiogenesis (as evidenced by HUVEC tube formation, egg CAM assay, and matrigel plug assays), significant inhibition of VEGFA synthesis and secretion and inhibition of nuclear NF- $\kappa B$ expression. In mice model inoculated with HT-29 and HCT116 cell xenografts, treatment by synthetic analogues of curcumin resulted in significant 
Table 1: Preclinical research in various forms of cancers from Indian Institutes

\begin{tabular}{ll}
\hline $\begin{array}{l}\text { Disease } \\
\text { category }\end{array}$ & Institute \\
\hline Breast & Chittaranjan National \\
& Cancer Institute, Kolkata \\
& Manipal College of Phar- \\
& maceutical Sciences, \\
& Manipal University, \\
& Waterford Institute of \\
& Technology of Ireland \\
& Indian Institute of Science, \\
& Bangalore \\
& \\
& \\
& School of Chemical \\
& Sciences (Solapur University) \\
& Rajiv Gandhi Centre \\
& for Biotechnology, Kerala \\
& Centre for Biomedical \\
& Engineering, Indian Institute \\
of Technology Delhi
\end{tabular}

Colorectal Chandigarh College of cancer Pharmacy, Punjab

Banasthali university (department of microbiology) in collaboration with Berhampur University (Odisha) and Emory University, (Georgia) Institute of Pharmacy (Nirma University, Ahmedabad)

Yogi Vemana University (Andhra Pradesh) in collaboration with along with Pennsylvania State University

Punjab University (Chandigarh)

Punjab University (Chandigarh)

LeukaemiaChristian Medical College, Vellore (Hematology department

National Cancer Institute, Kolkata (department of In vitro Carcinogenesis and Cellular Chemotherapy)

Calcutta School of Tropical
Key finding

Reference

Cancer chemo preventive potential of vanadium-based compound

Basu et al. (2017)

vanadium(III)-1-cysteine as an add on to cyclophosphamide

Developed PLA microspheres which demonstrated the feasibility of employing as biodegradable depot polymeric microspheres of anastrozole for long-term treatment of breast cancer

Primary breast cancers showing expression profile of TMP-28 (tripartite motif-containing protein-28) was associated with metastasis, stemness, resistance to chemotherapy and growth of tumor

Anticancer activity of extended conjugated indolyl-chalcones

Anticancer property of a novel copper carbohydrazone complex in a panel of cell lines with either wild or mutated BRCA-1

Established the role of trastuzumab and folic acid conjugated redox-responsive random multiblockco-polymericnanocarriers for treatment of breast cancer

Role of chitosan microsphere amalgamated curcumin-2-HP- $\beta-C D$ complex for selective delivery to colon by oral route

Evaluated the effect of curcumin and two synthetic analogues of it (UBS109 and EF31) on angiogenesis associated with colorectal cancer (HT-29 and HCT116 cell lines)

Evaluated the chemopreventive effect of $L$. usitatissimum extract

Shah et al. (2016) in colon cancer (associated with type 2 diabetes). They established the usefulness of this extract as a chemoprevention agent and this effect was found to be mediated through CDK4 inhibition

Evaluated the role of grape compounds on colon cancer stem cells

Shavi et al. (2017)

Damineni et al.

Bhale et al. (2017)

Nair et al. (2017)

Kumar et al. (2016)

Jyoti et al. (2016)

Rajitha et al. (2017)

Reddivari et al. (2016)

Fish oil has dose dependent effect upon mitochondrial impairments and it augments apoptosis and thus decreases carcinogenesis

Agnihotri et al. (2016)

Evaluated different ratios of corn oil and fish oil in experimental colon carcinogenesis and expression of different markers like Fas, Bax, Cyt-C and Bcl-2 expression

Proteasome inhibitor bortezomib, when given in combination with arsenic trioxide for treatment of acute promyelocytic leukemia; the combination therapy successfully abolished the micro-environmentmediated resistance to arsenic trioxide

$\mathrm{Cu}-5-\mathrm{SMAG}$ is a promising anti-leukemia agent (predominant proapoptotic action), effect of which is not dependent upon phenotype of MDR. Cu-5-SMAG overcomes MDR in T-cell ALL by its inhibitory effect upon expression of EGFR/PI3K/Akt and by causing redox imbalance

Sharma et al. (2016)

Ganesan et al. (2016)

Banerjee et al. (2016)

Mechanistic scenario of aberrations of p53 pathways (classical 
Medicine

$\begin{array}{ll}\text { Brain } & \text { Banaras Hindu University } \\ \text { cancer } & \text { Varanasi (Institute of } \\ & \text { Medical Sciences) }\end{array}$

Jadavpur University (Department of Pharmaceutical Technology)

Bharathiar University (Dept of Biotechnology, School of Biotechnology and Genetic Engineering) in collaboration with National Dong Hwa University, Taiwan University of Madras

IISc, Bangalore (Molecular Reproduction, Development and Genetics department), India

Kashmir University (Dept of Biotechnology

IIT Roorkee (Department of Mathematics)

Lung cancer

\section{Karunya University}

(Department of Biosciences and Technology), Coimbatore

Saurashtra University (Department of Chemistry) Sciences, Taiwan

Chittaranjan National Cancer Institute (Department of Immunoregulation and Immunodiagnostics)

Sahyadri Science College (Kuvempu University)

Cancer University of Kalyani cervix

(Department of Zoology) with Institute of Biomedical

and hematopoiesis specific) in ENU (ethyl nitrosourea) model of leukemia

Demonstrated that transferrin receptor targeted Docetaxel loaded d- $\alpha$-tocopherol polyethylene glycol 1000 succinate conjugated chitosan (TPGS-chitosan) nanoparticles had better cellular internalization, enhancement in relative bioavailability and cytotoxicity compared to their non-targeted counterpart

DTX-loaded nanoliposomes had better penetrability and thus it seems an important strategy to treat glioma with docetaxel

Evaluated the mechanism of action of HCD in brain tumor cell lines (glioma C6 and neuroblastoma N18 cell lines) and it was found that HCD induced autophagy was mediatyed via activation of ERK-1/2, p38 MAPK and ROS generation

Demonstrated that in glioma cell lines, Connexin 30 is an important modulator of IGF-1 receptor, which has actions like down-regulation of IGFR- 1 and abolition of ErK etc. Connexin 30 additionally potentiated the effect of inhibitors of IGF-R

In glioma cells, $\beta$-catenin signaling pathway is regulated by

Insulin-like growth factor binding protein-2 and it is a indicator of poor prognosis

Established the anti-neoplastic effect (C6 Glial Cells) of dasatinib and Caffeic Acid Phenethyl Ester

Developed a mathematical model to elucidate brain tumor abrogation by immunotherapy with T11TS

Used 1, 2-distearoyl-sn-glycero-3-phosphocholine (DSPC)

and cholesterol lipo-ATRA to investigate its molecular therapeutic

effect on lung cancer. The objective was to find whether it could enhance ATRA receptor, RAR- $\beta$ expression in lung cells as it was lost in case of lung cancer

Evaluated a series of novel chemicals "bis (hydroxymethyl) indolizino (8,7-b) indole" hybrids against the growth of SCLC H526 cells in xenograft model. It was found that amongst all the hybrids, compound 17a was more effective when compared to etoposide and cisplatin and equipotent to irinotecan

Demonstrated the high expression of D2 receptors in non-small

Roy et al. (2017)

cell lung cancer (CD133 positive). They also established that

D2 receptor activation was associated with inhibition of proliferation, which was associated with suppression of ERK1/2, AKT and down regulation of Oct-4 expression and MMP-9 (matrix metalloproteinase-9) secretion a cellular level

Established the role of $\mathrm{BP}-1 \mathrm{~B}$ in cancer associate angiogenesis

Thirusangu et al. (2017)

Evaluated the effects of Conium maculatum on cervical cancer

Mondal et al. (2014) in vitro and established its ability to induce apoptosis

Developed and characterized cisplatin loaded nanofibers for therapy of cervical cancer

Evaluated the anticancer property of six novel compounds cancer cervix cell lines (ME-180 and HeLa)

(2016)

Agrawal et al.

Shaw et al. (2017)

Thiyagarajan et al. (2016)

Arun et al. (2016)

Patil et al. (2016)

Balkhi et al. (2016)

Banerjee et al. (2015)

Berlin Grace et al. (2017)

Chang et al. (2017)

ISF College of Pharmacy, Punjab

CSIR-Indian Institute of Chemical Technology (Natural Products Chemistry Division) Hyderabad 


\begin{tabular}{|c|c|}
\hline \multirow[t]{8}{*}{$\begin{array}{l}\text { Hepato- } \\
\text { cellular } \\
\text { carcinoma }\end{array}$} & $\begin{array}{l}\text { CSIR-Centre for Cellular } \\
\text { and Molecular Biology, } \\
\text { Hyderabad }\end{array}$ \\
\hline & $\begin{array}{l}\text { Loyola College (Department } \\
\text { of Advanced Zoology and } \\
\text { Biotechnology), Chennai }\end{array}$ \\
\hline & $\begin{array}{l}\text { Nirma University (Institute } \\
\text { of Pharmacy), Gujrat }\end{array}$ \\
\hline & $\begin{array}{l}\text { Jamia Millia Islamia and } \\
\text { AIIMS, New Delhi }\end{array}$ \\
\hline & $\begin{array}{l}\text { Rajiv Gandhi Centre for } \\
\text { Biotechnology (Kerala) }\end{array}$ \\
\hline & $\begin{array}{l}\text { Pondicherry University } \\
\text { (Department of Biochemistry } \\
\text { and Molecular Biology, } \\
\text { Centre for Animal Research) }\end{array}$ \\
\hline & $\begin{array}{l}\text { Sam Higginbottom Institute } \\
\text { of Agriculture, Technology } \\
\text { and Sciences (Allahabad) }\end{array}$ \\
\hline & Annamalai University \\
\hline
\end{tabular}

NMIMS University

(Sunandan Divatia School

of Science)

IPGMER, Kolkata

Sam Higginbottom University of Agriculture, Technology \&Sciences, Allahabad

South Asian University, Chanakyapuri

Birla Institute of Technology, Mesra, Ranchi

Yogi Vemana University, (Department of Biotechnology \& Bioinformatics) Andhra Pradesh

Chittaranjan National Cancer Institute

Guru Nanak Dev University (Department of Botanical and Environmental Sciences) Amritsar

Academy of Scientific and Innovative Research (AcSIR), New Delhi
Characterized major pathways regulating this atypical EMT

through whole genome transcriptome profiling and molecular analysis, and identified a unique regulation of EMT by GSK-3 $\beta$

Evaluated antitumor Activity of Tetilladactyloidea (methanolic extract)

Oryzanol was found to be effective

Vanilin treatment inhibition of proliferation and decrease in mitochondrial production of ROS and reduction in mitochondrial membrance depolarization which resulted in enhanced apoptosis

Solanumnigrum Unripe fruit fraction decreased resistance to Adriamycin which was associated with down-regulating multi-drug resistance protein (Mdr)-1

Troxerutin with copper generates oxidative stress in cancer cells: Its possible chemotherapeutic mechanism against hepatocellular carcinoma

Triterpenoids principle of Wedeliacalendulaceainhibited tumerous growth. They may be acting through the NF- $\kappa$ B pathway

Chitosan nanoparticles protected Hepatocellular tissue against hepatocellular carcinoma induced by $\mathrm{N}$-diethylnitrosoamine

In insulin resistant liver cancer cell line (HepG2), Flavonoid content of Enicostemalittoraleblume enhanced glucose uptake by modulation of IRS-1/PI3K/Akt pathway

MiRNA199a-3p caused suppression of tumor growth, tumor invasion, migration and angiogenesis

Umbelliferon- $\alpha$-d-glucopyranosyl-(2I'!1II)- $\alpha$-Dglucopyranoside was effective in preventing DEN induced hepatic precancerous lesion development

Butyrate enhanced apoptiosis (mediated by ROS) and this occurred due to modulation of miR-22/SIRT-1 pathway

Found that some Schiff base analogues of 2-aminopyridine and 2-aminobezothiazole e.g. SSSC-33-((benzo[d]thiazol-2-ylimino) methyl)phenol) could effectively combat DEN induced hepatocellular damage

4 key genes were identified (ADH1A, ADH1C, CXCR4 and $\mathrm{ABCB} 1$ ) which were found to be associated with cancer of liver

In EAC bearing mice, selenium nanoparticles, when used in addition to cyclophaophamide, showed chemosensitizing and chemoprotective properties

P. vittata showed high potential as a cancer chemopreventive agent

Established the effect of PEGylated Betulinic acid (BA) in cancer therapy
Parveen et al. (2017)

Krishnan et al.

Panchal et al. (2017)

Nah et al. (2017)

Jagadeeshan

et al. (2017)

Subastri et al. (2017)

Verma et al. (2017)

Subhapradha et al. (2017)

Mokashi et al. (2017)

Ghosh et al. (2017)

Kumar et al. (2017)

Pant et al. (2017)

Chacko et al. (2017)

Gupta et al. (2017)

Bhattacharya et al. (2017)

Kaur et al. (2017)

Saneja et al. (2017) 
inhibition of growth of tumor and potentiation of effects of other anticancer agents like 5-FU and oxaliplatin.

Shah et al. (2016) from institute of Pharmacy (Nirma University, Ahmedabad) evaluated the chemopreventive effect of $L$. usitatissimum extract in colon cancer (associated with type 2 diabetes). They established the usefulness of this extract as a chemoprevention agent and this effect was found to be mediated through CDK4 inhibition. Reddivari et al. (2016) from Yogi Vemana University (Andhra Pradesh) in collaboration with along with Pennsylvania State University evaluated the role of grape compounds on colon cancer stem cells. Grape compounds significantly suppressed colon cancer stem cells both in vitro and in vivo (rodent model) and this inhibitory effect was potentially mediated by $\mathrm{Wnt} / \beta$ catenin signaling pathway.

Mitochondria plays an important role in cell bioenergetics and apoptosis. Impairment in the mitochondrial electron transport chain (ETC) is an important factor mediating uncontrolled proliferation in carcinogenesis. Researchers from Punjab University (Chandigarh) found that fish oil has dose dependent effect upon mitochondrial impairments and it augments apoptosis and thus decreases carcinogenesis (Agnihotri et al., 2016).

Another group of researchers from Punjab University evaluated different ratios of corn oil and fish oil in experimental colon carcinogenesis and expression of different markers like Fas, Bax, Cyt-C and $\mathrm{Bcl}-2$ expression. Treatment resulted in activation of intrinsic apoptotic pathway (as evidenced by increase in Cyt c release and Bax expression and decrease in Bcl-2 levels). (Sharma et al. 2016).

\section{Leukaemia}

Compounds with pyrazole moiety are important class of heterocyclic compounds. Department of Chemistry, Mysore University evaluated 1-aryl-3, 5-bis (het) aryl pyrazole derivatives against various cancer cell lines and found that 3-(1-(4-bromophenyl)-5-phenyl-1Hpyrazol-3-yl) pyridine (5d) had maximal anticancer activity particularly against leukemia and breast cancer cells (Ananda et al., 2017).

Drug resistance is an important predictor of outcome of cancer chemotherapy. Researchers from
Christian Medical College, Vellore (Hematology department) showed that protea some inhibitor bortezomib, when given in combination with arsenic trioxide for treatment of acute promyelocytic leukemia; the combination therapy successfully abolished the micro-environment-mediated resistance to arsenic trioxide (Ganesan et al., 2016). Researchers from National Cancer Institute, Kolkata (Department of In Vitro Carcinogenesis and Cellular Chemotherapy)showed that $\mathrm{Cu}-5-\mathrm{SMAG}$ is a promising anti-leukemia agent (predominant proapoptotic action), effect of which is not dependent upon phenotype of MDR. Cu-5-SMAG overcomes MDR in T-cell ALL by its inhibitory effect upon expression of EGFR/PI3K/Aktand by causing redox imbalance (Banerjee et al., 2016). Another group from Department of Biochemistry and Medical Biotechnology (Stem Cell Research and Application Unit), Calcutta School of Tropical Medicine evaluated the mechanistic scenario of aberrations of p53 pathways (classical and hematopoiesis specific) in ENU (ethyl nitrosourea) model of leukemia (Chatterjee et al., 2016). Das et al. (2016) established the regulatory role of estrogen receptor- alpha on casein kinase 2 alpha and its subsequent effect on enhancement of AKT activity and PML (tumor suppressor) degradation, resulting in increased cellular proliferation, migration and metastasis. Another group of researchers found that injectable chitosan- $\hat{a}-$ glycerophosphate gel amalgamated vincristine sulfate loaded dextran microspheres offered advantages like enhanced cytotoxicity on human leukemia cells (both in vitro and in-vivo) compared to the traditional formulation (Thakur et al., 2016). In a mouse transplantable acute promyelocytic leukemia (APL) model, Patel et al. (2015) established the efficacy of immunotherapy (nonspecific DNA construct pVAX14) on survival when given in combination with ATRA (all-trans retinoic acid).

\section{Brain Cancer}

A group from Banaras Hindu University, Varanasi (Institute of Medical Sciences), demonstrated that transferrin receptor targeted Docetaxel loaded d-átocopherol polyethylene glycol 1000 succinate conjugated chitosan (TPGS-chitosan) nanoparticles had better cellular internalization, enhancement in relative bioavailability and cytotoxicity compared to their non-targeted counterpart (Agrawal et al., 2017). 
In in-vitro settings, Docetaxel (DTX) is very promising against glioma. However blood brain permeability limits its use. Shawet al.,(2017) from Jadavpur University (Department of Pharmaceutical Technology) established that DTX-loaded nanoliposomes had better penetrability and thus it seems an important strategy to treat glioma with docetaxel. Bhattacharya et al. (2017) earlier demonstrated that in rodent glioma model, administration of sheep erythrocyte membrane glycopeptide T11-target structure is associated with apoptosis in glioma-associated brain endothelial cells and this effect is mediated via accumulation of p53 and associated inhibition of Raf/MEK/ERK and PI3K/ Akt pathway which can provide critical insight to its mechanism of action.

16-hydroxy-cleroda-3,13-dien-16,15-olide (HCD), is a novel medicinal compound isolated from the plant "Polyalthialongifolia" has significant action on brain tumor cells. Bharathiar University (Department of Biotechnology, School of Biotechnology and Genetic Engineering) in collaboration with National Dong Hwa University, Taiwan evaluated the mechanism of action of HCD in brain tumor cell lines (glioma C6 and neuroblastoma N18 cell lines) and it was found that HCD induced autophagy was mediated via activation of ERK-1/2, p38 MAPK and ROS generation. (Thiyagarajan et al., 2016). Arun et al. (2016) from University of Madras demonstrated that in glioma cell lines, Connexin 30 is an important modulator of IGF-1 receptor, which has actions like down-regulation of IGFR-1 and abolition of ErK etc. Connexin 30 additionally potentiated the effect of inhibitors of IGFR. Patil et al. (2016) from IISc, Bangalore (Molecular Reproduction, Development and Genetics department), India found that in glioma cells, âcatenin signaling pathway is regulated by Insulin-like growth factor binding protein- 2 and it is a indicator of poor prognosis. Balkhi et al. (2016) from Kashmir University (Department of Biotechnology) found established the anti-neoplastic effect (C6 Glial Cells) of dasatinib and Caffeic Acid Phenethyl Ester. Bhuvanalakshmi et al. (2015) established that the role of sFRP4 (secreted frizzled-related protein 4) which is a WNT agonist in epithelia-mesenchymal transition from their work using human glioblastoma cell lines U373 and U87. sFRP4 also acted as a chemosensitizer to temozolamide by reversing this transition. Banerjee et al. (2015) from IIT Roorkee (Department of Mathematics) developed a mathematical model to elucidate brain tumor abrogation by immunotherapy with T11TS.

\section{Lung Cancer}

All Trans Retinoic acid (ATRA) is an efficient drug for leukemia, but is not efficient therapy for solid cancers. Berlin Grace et al. (2017) from, Karunya University (Department of Biosciences and Technology), Coimbatore used 1,2-distearoyl-snglycero-3-phosphocholine (DSPC) and cholesterol lipo-ATRA to investigate its molecular therapeutic effect on lung cancer. The objective was to find whether it could enhance ATRA receptor, RAR- $\beta$ expression in lung cells as it was lost in case of lung cancer. The study was done in experimental C57BL/ 6 mice model developed by inoculation of B16F10 and A549 human lung cancer cells.Both free and lipoATRA treatments showed an enhancement of RAR$\beta$ protein and gene expressions, indicating its induction on RAR $\beta$. However, the effect of lipo-ATRA was more compared to free ATRA treatment. Saurashtra University (Department of Chemistry), in collaboration with Institute of Biomedical Sciences, Taiwan evaluated a series of novel chemicals "bis(hydroxymethyl) indolizino (8,7-b) indole" hybrids against the growth of SCLC H526 cells in xenograft model. It was found that amongst all the hybrids, compound 17a was more effective when compared to etoposide and cisplatinand equipotent to irinotecan (Chang et al., 2017). Roy et al. (2017) from Chittaranjan National Cancer Institute (Department of Immunoregulation and Immunodiagnostics) demonstrated the high expression of D2 receptors in non-small cell lung cancer (CD133 positive). They also established that D2 receptor activation was associated with inhibition of proliferation, which was associated with suppression of ERK1/2, AKT and down regulation of Oct-4 expression and MMP9(matrix metalloproteinase-9) secretion a cellular level. Thirusangu et al. (2017), from Sahyadri Science College (Kuvempu University) established the role of BP-1B in cancer associate angiogenesis. Hudilkar et al. (2017) evaluated the chemo preventive effect of polyphenolic content of black tea and mechanism of this action in a model of lung cancer [benzo(a)pyrene and 4-(methylnitrosamino)-1-(3pyridyl)-1- butanone-induced lung cancer] in $\mathrm{A} / \mathrm{J}$ mice. 
They found that the chemopreventive effect of polymeric black tea polyphenols (PBPs) was due to inhibition of inflammation and cellular proliferation and enhanced apoptosis and the molecular mechanisms included down-regulation of p38 and Akt phosphorylation.

\section{Cancer Cervix}

Mondal et al. (2014) from University of Kalyani (Department of Zoology) evaluated the effects of Conium maculatum on cervical cancer in vitro and established its ability to induce apoptosis. Prabhavathy et al. (2015) evaluated the effects of TNF- $\alpha$ on NF$\beta \mathrm{B}$ expression in SiHa cells integrated with HPV16 E2. TNF-alpha sensitized NF- $\kappa B$ expression and the net effect resulted was increased senescence and survival. Mondal et al. 2015 established that in HPV 39 infected cervical cancer cell lines (ME-180 cell lines), artemisinin induced anti-proliferative and apoptosis inducing effect by repressing telomerase subunits and induction of apoptosis. Agarwal et al. 2017 from ISF College of Pharmacy, Punjab developed and characterized cisplatin loaded nanofibers for therapy of cervical cancer. Mallavadhani et al. (2014) from, CSIR-Indian Institute of Chemical Technology (Natural Products Chemistry Division) Hyderabad evaluated the anticancer property of six novel compounds in cancer cervix cell lines (ME-180 and HeLa).

\section{Hepatocellular Cancer}

Lot of good quality and important topics were addressed by researchers with regards to research in Hepatocellular cancer. Some of the research studies are shown in Table 1. Most studies used either cell line or chemical method to induce carcinogenesis. The studies ranged from characterization of novel compounds, plant extracts to elucidation of molecular pathway. Among all the cancers, hepatocellular cancer is one of the most explored areas among Indian researchers in preclinical research.

\section{Status of Clinical Cancer Research in India}

We collected data from CTRI, PubMed and clinicaltrials.gov top collect data on clinical research using different filters and keywords. Till now 1066 studies are registered in CTRI. The spectrum of studies comprised of randomized to non-randomized studies. Details are shown in Fig. 1. Among the completed studies, number of phase 3 studies $(n=52)$ was highest, followed by phase 2 studies $(n=37)$ compared to phase 1 studies. But the number was quite less when compared to data from USA. Number of multinational studies were also less (130 in India versus 2805 in USA), similar were result of metaanalysis and observational studies (data shown in Fig. 2).

\section{Number of clinical studies registered in CTRI}

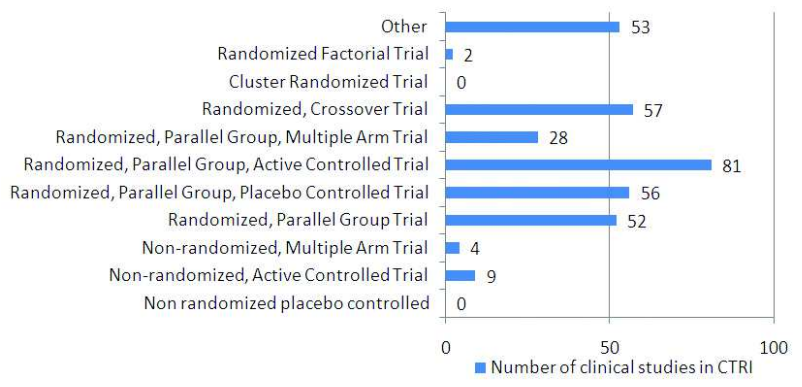

Fig. 1: Clinical studies registered in CTRI (design wise)

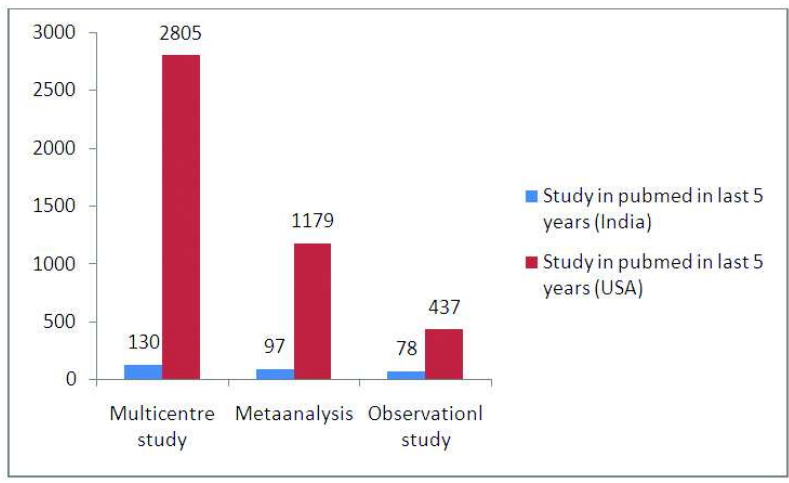

Fig. 2: Studies published in last 5 years (data obtained from PubMed)

So, to summarize, although India is progressing in terms of clinical research in cancer the pace is slow compared to developed country like USA. And some states of India are lagging behind. Government can take proper initiative in the same to improve the infrastructure and educational status of those states for further improvement.

\section{Concluding Remarks}

Many promising compounds are reported in preclinical research, but success rate in clinical trial is meager. DNA Ligase IV is responsible for sealing of doublestrand breaks (DSBs) during nonhomologous end- 
joining (NHEJ). SCR7 inhibits ligase IV in a dose dependent manner and which further activated intrinsic apoptotic pathways (Srivastava et al., 2012). Later it was found that these agents were neither selective nor potent inhibitors of DNA ligase IV (Greco et al., 2016). Compared to the amount of preclinical

\section{Reference}

Aggarwal U, Goyal A K and Rath G (2017) Development and characterization of the cisplatin loaded nanofibers for the treatment of cervical cancer Mater Sci Eng C Mater Biol Appl 75 125-132

Agnihotri N, Sharma G, Rani I, Renuka and Bhatnagar A (2016) Fish oil prevents colon cancer by modulation of structure and function of mitochondria Biomed Pharmacother $\mathbf{8 2}$ 90-7

Agrawal P, Singh R P, Sonali, Kumari L, Sharma G, Koch B, Rajesh C V, Mehata A K, Singh S, Pandey B L and Muthu M S (2017) TPGS-chitosan cross-linked targeted nanoparticles for effective brain cancer therapy Mater Sci Eng C Mater Biol Appl 74 167-176

Ananda H, Sharath Kumar K S, Nishana M, Hegde M, Srivastava M, Byregowda R, Choudhary B, Raghavan S C and Rangappa K S (2017) Regio selective synthesis and biological studies of novel 1-aryl-3, 5-bis (het) aryl pyrazole derivatives as potential antiproliferative agents Mol Cell Biochem 426 149-160

Arun S, Vanisree A J and Ravisankar S (2016) Connexin 30 downregulates Insulin-like growth factor receptor-1, abolishes Erk and potentiates effects of an IGF-R inhibitor in a glioma cell line Brain Res 1643 80-90

Balkhi H M, Gul T and Haq E (2016) Anti-neoplastic and calcium modulatory action of caffeic acid phenethyl ester and dasatinib in C6 glial cells: A therapeutic perspective CNS Neurol Disord Drug Targets 15 54-63

Banerjee K, Das S, Sarkar A, Chatterjee M, Biswas J and Choudhuri S K (2016) A copper chelate induces apoptosis and overcomes multidrug resistance in T-cell acute lymphoblastic leukemia through redox imbalance and inhibition of EGFR/PI3K/Akt expression Biomed Pharmacother 84 71-92

Banerjee S, Khajanchi S and Chaudhuri S (2015) A mathematical model to elucidate brain tumor abrogation by immunotherapy with T11 target structure PLoS One $\mathbf{1 0}$

Basu A, Bhattacharjee A, Baral R, Biswas J, Samanta A and Bhattacharya S (2017) Vanadium (III)-1-cysteine enhances work, clinical translation is very less. This seems to be due to dissociation between preclinical and clinical research institutes or research departments. A good collaborative environment can improve cancer research status in India.

the sensitivity of murine breast adenocarcinoma cells to cyclophosphamide by promoting apoptosis and blocking angiogenesis Tumour Biol 39

Berlin Grace V M, Reji R M and Sundaram V (2017) Enhanced expression of tumour suppressor RAR-â by DSPC nanoformulated lipo-ATRA in the lung of B16F10 cellimplanted C57BL6 mice and in A549 cells Life Sci 184 1017

Bhale P S, Chavan H V, Dongare S B, Shringare S N, Mule Y B, Nagane S S and Bandgar B P (2017) Synthesis of extended conjugated indolylchalcones as potent anti-breast cancer, anti-inflammatory and antioxidant agents Bioorg Med Chem Lett 27 1502-1507

Bhattacharya D, Singh M K, Chaudhuri S, Datta A and Chaudhuri S (2017) T11TS Treatment Augments Apoptosis of Glioma Associated Brain Endothelial Cells, Hint Toward AntiAngiogenic Action in Glioma J Cell Physiol 232 526-539

Bhattacharjee A, Basu A, Biswas J, Sen T and Bhattacharya S (2017) Chemoprotective and chemosensitizing properties of selenium nanoparticle (Nano-Se) during adjuvant therapy with cyclophosphamide in tumor-bearing mice $\mathrm{Mol} \mathrm{Cell}$ Biochem 424 13-33

Bhuvanalakshmi G, Arfuso F, Millward M, Dharmarajan A and Warrier S (2015) Secreted frizzled-related protein 4 inhibits glioma stem-like cells by reversing epithelial to mesenchymal transition, inducing apoptosis and decreasing cancer stem cell propertiesPLoS One $\mathbf{1 0}$

Chacko S and Samanta S (2017) A novel approach towards design, synthesis and evaluation of some Schiff base analogues of 2-aminopyridine and 2-aminobezothiazole against hepatocellular carcinoma Biomed Pharmacother 89 162176

Chang S M, Christian W, Wu M H, Chen T L, Lin Y W, Suen C S, Pidugu H B, Detroja D, Shah A, Hwang M J, Su T L and Lee T C (2017) Novel indolizino[8,7-b]indole hybrids as anti-small cell lung cancer agents: Regioselective modulation of topoisomerase II inhibitory and DNA crosslinking activities Eur J Med Chem 127 235-249

Chatterjee R, Chattopadhyay S and Law S (2016) Alteration of 
classical and hematopoiesis specific p53 pathway in the bone marrow hematopoietic stem/progenitor compartment facilitates leukemia progression in experimental mice Leuk Res 47 70-7

Damineni S, Balaji S A, Shettar A, Nayanala S, Kumar N, Kruthika B S, Subramanian K, Vijayakumar M, Mukherjee G, Gupta $\mathrm{V}$ and Kondaiah P (2017) Expression of tripartite motifcontaining protein 28 in primary breast carcinoma predicts metastasis and is involved in the stemness, chemoresistance, and tumor growth Tumour Biol 39

Das N, Datta N, Chatterjee U and Ghosh M K (2016) Estrogen receptor alpha transcriptionally activates casein kinase 2 alpha: A pivotal regulator of promyelocyticleukaemia protein (PML) and AKT in oncogenesis Cell Signal 28 675-87

Ganesan S, Alex AA, Chendamarai E, Balasundaram N, Palani H K, David S, Kulkarni U, Aiyaz M, Mugasimangalam R, Korula A, Abraham A, Srivastava A, Padua R A, Chomienne C, George B, Balasubramanian P and Mathews V (2016) Rationale and efficacy of proteasome inhibitor combined with arsenic trioxide in the treatment of acute promyelocytic leukemia Leukemia 30 2169-2178

Ghosh A, Dasgupta D, Ghosh A, Roychoudhury S, Kumar D, Gorain M, Butti R, Datta S, Agarwal S, Gupta S, Krishna Dhali G, Chowdhury A, Schmittgen T D, Kundu G C and Banerjee S (2017) MiRNA199a-3p suppresses tumor growth, migration, invasion and angiogenesis in hepatocellular carcinoma by targeting VEGFA, VEGFR1, VEGFR2, HGF and MMP2 Cell Death Dis 8

Greco G E, Matsumoto Y, Brooks R C, Lu Z, Lieber M R and Tomkinson A E (2016) SCR7 is neither a selective nor a potent inhibitor of human DNA ligase IV DNA Repair (Amst) 43 18-23

Gupta M K, Behara S K and Vadde R (2017)I n silico analysis of differential gene expressions in biliary stricture and hepatic carcinoma Gene 597 49-58

Hudlikar R R, Venkadakrishnan V B, Kumar R, Thorat R A, Kannan S, Ingle AD, Desai S, Maru G B and Mahimkar M B (2017) Polymeric black tea polyphenols (PBPs) inhibit benzo(a)pyrene and 4-(methylnitrosamino)-1-(3-pyridyl)1-butanone-induced lung carcinogenesis potentially through down-regulation of p38 and Akt phosphorylation in A/J mice Mol Carcinog 56 625-640

Jagadeeshan S, David D, Jisha S, Manjula S, Asha Nair SSolanumnigrum Unripe fruit fraction attenuates Adriamycin resistance by down-regulating multi-drug resistance protein (Mdr)-1 through Jak-STAT pathway BMC Complement Altern Med 17370
Jyoti K, Bhatia R K, Martis E A F, Coutinho E C, Jain U K, Chandra R and Madan J (2016) Solublecurcumin amalgamated chitosan microspheres augmented drug delivery and cytotoxicity in colon cancer cells: In vitro and in vivo study Colloids Surf B Biointerfaces 148 674-683

Kaur P, Kumar M, Singh A P and Kaur S (2017) Ethyl acetate fraction of Pterisvittata L. alleviates 2-acetylaminofluorene induced hepatic alterations in male Wistar rats Biomed Pharmacother 88 1080-1089

Krishnan G S, Rajagopal V, Antony Joseph S R, Sebastian D, Savarimuthu I, Selvaraj K R N and Thobias A F (2017) In vitro, in silico and in vivo antitumor activity of crude methanolic extract of Tetilladactyloidea (Carter, 1869) on DEN induced HCC in a rat model Biomed Pharmacother 95 795-807

Kumar A, Lale S V, Aji Alex M R, Choudhary V and Koul V (2017) Folic acid and trastuzumab conjugated redox responsive random multiblockcopolymericnanocarriers for breast cancer therapy: In-vitro and in-vivo studies Colloids Surf B Biointerfaces 149 369-378

Kumar V, Bhatt P C, Rahman M, Al-Abbasi F A, Anwar F and Verma A (2017) Umbelliferon- $\alpha$-d-glucopyranosyl(2(I)'!1(II))- $\alpha$-D-glucopyranoside ameliorates diethylnitrosamine induced precancerous lesion development in liver via regulation of inflammation, hyperproliferation and antioxidant at pre-clinical stage Biomed Pharmacother 94 834-842

Mallavadhani U V, Prasad C V, Shrivastava S and Naidu V G (2014) Synthesis and anti-cancer activity of some novel 5,6-fused hybrids of juglone based 1,4-naphthoquinones Eur J Med Chem 83 84-91

Mondal A and Chatterji U (2015) Artemisinin represses telomerase subunits and induces apoptosis in HPV-39 infected human cervical cancer cells J Cell Biochem 116 1968-81

Mondal J, Panigrahi A K and Khuda-Bukhsh A R (2014) Anticancer potential of Coniummaculatum extract against cancer cells in vitro: Drug-DNA interaction and its ability to induce apoptosis through ROS generation Pharmacogn Mag 10 S524-33

Mokashi P, Khanna A and Pandita N (2017) Flavonoids from Enicostemalittoraleblume enhances glucose uptake of cells in insulin resistant human liver cancer (HepG2) cell line via IRS-1/PI3K/Akt pathway Biomed Pharmacother 90 268-277

Murthy N S, Chaudhry K and Rath G K (2008) Burden of cancer and projections for 2016, Indian scenario: gaps in the availability of radiotherapy treatment facilities Asian Pac J Cancer Prev 9 671-7 
Nair R S, Potti M E, Thankappan R, Chandrika S K, Kurup M R and Srinivas P (2017) Molecular trail for the anticancer behavior of a novel copper carbohydrazone complex in BRCA1 mutated breast cancer Mol Carcinog 56 15011514

National cancer registry (2007-2011 report) http://ncrpindia.org/ Annual_Reports.aspx (assessed on 25/09/2017)

Naz H, Tarique M, Khan P, Luqman S, Ahamad S, Islam A, Ahmad F and Hassan M I (2017) Evidence of vanillin binding to CAMKIV explains the anti-cancer mechanism in human hepatic carcinoma and neuroblastoma cells $\mathrm{Mol}$ Cell Biochem (in press)

Panchal S S, Ghatak S B, Jha A B and Onattu R (2017) Reduction of liver tumerogenic effect of $\mathrm{N}$-nitrosodiethylamine by treatment with c-oryzanol in Balb/C mice Environ Toxicol Pharmacol 56 86-98

Pant K, Yadav A K, Gupta P, Islam R, Saraya A and Venugopal S K (2017) Butyrate induces ROS-mediated apoptosis by modulating miR-22/SIRT-1 pathway in hepatic cancer cells Redox Biol 12 340-349

Parveen S, Vedagiri D, Nair H G, Parthasarathy H and Harshan K H (2017) Unconventional MAPK-GSK-3â pathway behind atypical epithelial-mesenchymal transition in hepatocellular carcinoma Sci Rep 78842

Patel S, Guerenne L, Gorombei P, Omidvar N, Schlageter M H, Alex AA, Ganesan S, West R, Adès L, Mathews V, Krief P, Pla M, Fenaux P, Chomienne C and Padua R A (2015) pVAX14DNA-mediated add-on immunotherapy combined with arsenic trioxide and all-trans retinoic acid targeted therapy effectively increases the survival of acute promyelocytic leukemia mice Blood Cancer J 5 e374

Patil S S, Gokulnath P, Bashir M, Shwetha S D, Jaiswal J, Shastry A H, Arimappamagan A, Santosh V and Kondaiah P (2016) Insulin-like growth factor binding protein-2 regulates $\beta$ catenin signaling pathway in glioma cells and contributes to poor patient prognosis Neuro Oncol 18 1487-1497

Prabhavathy D, Subramanian C K and Karunagaran D (2015) Reexpression of HPV16 E2 in SiHa (human cervical cancer) cells potentiates NF- $\beta$ B activation induced by TNF- $\kappa$ concurrently increasing senescence and survival Bioscience Reports 35 e00175

Rajitha B, Nagaraju G P, Shaib W L, Alese O B, Snyder J P, Shoji M, Pattnaik S, Alam A and El-Rayes B F (2017) Novel synthetic curcumin analogs as potent antiangiogenic agents in colorectal cancer Mol Carcinog 56 288-299

Reddivari L, Charepalli V, Radhakrishnan S, Vadde R, Elias R J, Lambert J D and Vanamala J K (2016) Grape compounds suppress colon cancer stem cells in vitro and in a rodent model of colon carcinogenesis BMC Complement Altern Med 16278

Roy S, Lu K, Nayak M K, Bhuniya A, Ghosh T, Kundu S, Ghosh S, Baral R, Dasgupta P S and Basu S (2017) Activation of D2 Dopamine Receptors in CD133+ve Cancer Stem Cells in Non-small Cell Lung Carcinoma Inhibits Proliferation, Clonogenic Ability, and Invasiveness of These Cells J BiolChem 292 435-445

Saranath D and Khanna A (2014) Current status of cancer burden global and Indian scenario Biomed Res J 1 1-5

Saneja A, Sharma L, Dubey R D, Mintoo M J, Singh A, Kumar A, Sangwan P L, Tasaduq S A, Singh G, Mondhe D M and Gupta P N (2017) Synthesis, characterization and augmented anticancer potential of PEG-betulinic acid conjugate Mater Sci Eng C Mater Biol Appl 73 616-626

Shah N R and Patel B M (2016) Secoisolariciresinoldiglucoside rich extract of L.usitatissimum prevents diabetic colon cancer through inhibition of CDK4 Biomed Pharmacother $83733-739$

Sharma G, Rani I, Bhatnagar A and Agnihotri N (2016) ApoptosisMediated Chemoprevention by Different Ratios of Fish Oil in Experimental Colon Carcinogenesis Cancer Invest 34 220-30

Shaw T K, Mandal D, Dey G, Pal M M, Paul P, Chakraborty S, Ali K A, Mukherjee B, Bandyopadhyay A K and Mandal M (2017) Successful delivery of docetaxel to rat brain using experimentally developed nanoliposome: a treatment strategy for brain tumor Drug Deliv 24 346-357

Shavi G V, Nayak U Y, Reddy M S, Ginjupalli K, Deshpande P B, Averineni R K, Udupa N, Sadhu S S, Danilenkoff C and Raghavendra R (2017) A novel long-acting biodegradable depot formulation of anastrozole for breast cancer therapy Mater Sci Eng C Mater Biol Appl 75 535-544

Srivastava M, Nambiar M, Sharma S, Karki S S, Goldsmith G, Hegde M, Kumar S, Pandey M, Singh R K, Ray P, Natarajan R, Kelkar M, De A, Choudhary B and Raghavan S C (2012) An inhibitor of nonhomologous end-joining abrogates double-strand break repair and impedes cancer progression Cell 151 1474-87

Subastri A, Suyavaran A, Preedia Babu E, Nithyananthan S, Barathidasan R and Thirunavukkarasu C (2018) Troxerutin with copper generates oxidative stress in cancer cells: Its possible chemotherapeutic mechanism against hepatocellular carcinoma J Cell Physiol 233 1775-1790

Subhapradha N, Shanmugam V and Shanmugam A (2017) Chitosan nanoparticles from marine squid protect liver cells against $\mathrm{N}$-diethylnitrosoamine-induced Hepatocellular carcinoma Carbohydr Polym 171 18-26 
Sullivan R, Badwe R A, Rath G K, Pramesh C S, Shanta V, Digumarti R, D'Cruz A, Sharma S C, Viswanath L, Shet A, Vijayakumar M, Lewison G, Chandy M, Kulkarni P, Bardia M R, Kumar S, Sarin R, Sebastian P, Dhillon PK, Rajaraman P, Trimble E L, Aggarwal A, Vijaykumar D K and Purushotham AD (2014) Cancer research in India: national priorities, global results Lancet Oncol 15 e213-222

Thakur V, Kush P, Pandey R S, Jain U K, Chandra R and Madan J (2016) Vincristine sulfate loaded dextran microspheres amalgamated with thermosensitive gel offered sustained release and enhanced cytotoxicity in THP-1, human leukemia cells: In vitro and in vivo study Mater Sci Eng C Mater Biol Appl 61 113-122

Thirusangu P, Vigneshwaran V, Ranganatha V L, Vijay Avin B R, Khanum S A, Mahmood R, Jayashree K and Prabhakar B T (2017) A tumouralangiogenic gateway blocker,
Benzophenone-1B represses the HIF-1 $\alpha$ nuclear translocation and its target gene activation against neoplastic progression Biochem Pharmacol 125 26-40

Thiyagarajan V, Sivalingam K S, Viswanadha V P and Weng C F (2016) 16-hydroxy-cleroda-3,13-dien-16,15-olide induced glioma cell autophagy via ROS generation and activation of p38 MAPK and ERK-1/2 Environ Toxicol Pharmacol 45 202-211

Verma A, Singh D, Anwar F, Bhatt P C, Al-Abbasi F and Kumar V (2017) Triterpenoids principle of Wedeliacalendulacea attenuated diethynitrosamine-induced hepatocellular carcinoma via down-regulating oxidative stress, inflammation and pathology via NF- $\kappa$ B pathway Inflammopharmacology doi: 10.1007/s10787-017-03503. [Epub ahead of print]. 